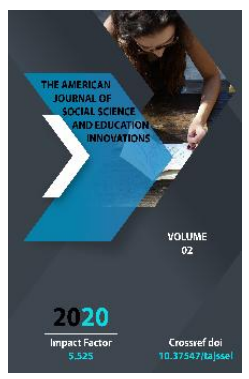

\title{
Basic Concepts Of Linguocultural Studies
}

\author{
Durdona Karimova Farxodovna \\ Senior Lecturer Of The Department Of General Education Disciplines, Specialized Branch Of \\ Tashkent State University Of Law, Uzbekistan
}

Journal Website:

http://usajournalshub.c

om/index,php/tajssei

Copyright: Original

content from this work

may be used under the

terms of the creative

commons attributes

4.0 licence.

\section{ABSTRACT}

The article highlights the notion of language and culture, their tight connections in foreign language acquisition. Presented the brief overview of target language interpretation considering the national traditions, history, literature, life style, economic and cultural studies of the nation. It also states the vital contribution of Linguoculture in exploring the interrelationship and influence of language with culture. Moreover, a deep view is presented on linguoculturemes to be one of the most important concepts in linguocultural studies as well as their classification is listed.

\section{KEYWORDS}

Language, culture, linguoculture, linguocultureme, socio-culture, image, interpretation, concept

\section{INTRODUCTION}

At present, knowing a foreign language and mastering it is becoming a modern requirement all over the world. It is well known that everyone belongs to a specific culture that includes national traditions, language, history, literature. International economic, cultural and scientific relations have led to the interpretation of language as a means of reflecting culture. As E.Sepir points out, language is a guiding tool in the study of culture. When learning a language, it is important to know not only the words, 
language chunks and speech but also the culture, worldview, lifestyle and customs of the country of the target language. This, in turn, has led to the emergence of a new field in linguistics, namely, the evolution of linguocultural studies[1].

Linguocultural studies is a complex branch of science that has emerged on the basis of the interplay of linguistics and culture. It studies the interrelationship and influence of language with culture, language as a phenomenon of culture. This is the view of the world to a certain extent through the prism of a national language, the manifestation of language through the mind and culture of a particular nation. Due to its novelty and the fact that it has not been fully studied in its entirety and the existence of different opinions and views still requires a lot of scientific research.

The determinism between language and culture, that is, the interdependence of one another, is true reciprocity[2]. Therefore, it is natural that scientists from different countries study the issue of language and culture in various directions. This problem is discussed by notable linguists (Yu.Sorokin, V.Telia, E.Vereshchagin, A.Vejbitskaya, V.Kostomarov, D.Olford, D.Chaims and others) and philosophers (G.Brutyan, E.Markaryan and others), psychologists ( L.Vygotsky, A.Leontev, V.Petrenko, P.Gulviste). This issue plays an important role in the research on speech culture. (Yu.Skvortsov, E.Begmatov, A.Mamatov, B.Urinbaev and others). In recent years, the evolvement of linguistics as a separate field of research in linguistics (A.Krasnykh, V.Maslova, D.Gudkov, D.Ashurova) has led to the actuality of this issue.
E.Sepir and B.Wharf, in their hypotheses, promote the harmony of language and culture, interpreting language as a product of culture and at the same time a factor shaping culture [3]. After all, any culture manifests itself in language, finds its own material shell in language, develops and changes under the influence of the environment.

A Russian philologist S.G.Ter-Minasova symbolizes a language to a cultural treasure[4]. According to his approach, language preserves cultural values in its vocabulary, grammar, idiom, articles, folklore, fiction and scientific literature, as well as in oral and written speech. If we look at the structure, expression and methods of acquisition of language, then the sociocultural layer or component of culture is manifested as part of the language or the basis of its existence.

Language is a major social weapon that forms social currents on an ethnic scale, preserves and transmits the culture, traditions, and social consciousness of a community that speaks the same language, thereby creating the basis for the foundation of nations. When language is used as the main symbol of a nation it can be observed from two sides: inside and outside. When viewed as a process that takes place 'from within', language emerges as one of the important factors in the mutual integration of peoples. Externally, one ethnic group can be seen as a distinguishing feature from other ethnic groups.

One of the most important concepts in linguocultural studies is linguocultureme. Linguocultureme is a unit of language or speech that reflects a piece of culture in its semantics (meaning). It includes words that reflect a part of a culture (primitive, artificial, 
compound, and compound words), phraseological units, phrases, sentences, speech clichés, complex syntactic units, texts, including folklore texts, and so on. Linguocultureme has a plan of content and expression. The plan of expression consists of the units mentioned above, and the plan of content involves the semantics of those units. Hence, linguocultureme differs from the concept in that it is a unit of language or speech, with a system of expression and content.

V.A.Maslova notes that there are 9 types of linguocultureme[5]:

1. Non-equivalent vocabulary;

2. Mythological language units;

3. The paremiological fund of a language;

4. Phraseological fund of a language;

5. Symbols, stereotypes;

6. Metaphors and images of a language;

7. Stylistic content of a language;

8. Verbal Behavior;

9. Speech etiquette.

One of the basic concepts of linguocultural studies is the concept of worldview. Scientists distinguish two types of images - conceptual and linguistic worldviews. Conceptual image of the world means an idea that arises in the human mind on the basis of a certain life reality based on the experience of life. Language represents all the phenomena reflected in the activity of thinking, and it is closely connected with the practical activity of man. The existence of language makes the expression of a "conceptual image of the world" one of the main problems of analysis. In this sense, the conceptual image of the world is the sum of knowledge about human existence, and the world image in language is the linguistic understanding of the world.
The concept of a linguistic image of the world is consistent not only with the concept of a world image, but also with the notion of a conceptual image of the world. Language plays a vital role in the process of conceptualization of the universe. The linguistic image of the world reveals a conceptual image of the world. As E.Kubryakova notes, "the conceptual image of the world is realized through language, a certain part of which is imprinted on the human psyche through other types of mental representations - images, schemes, images (pictures)"'[6].

The conceptual image of the world becomes wider and richer than the linguistic image of the world; the shell of the linguistic image of the world is depicted as a layer subordinate to the conceptual image of the world, and the conceptual image covers different zones of language influence. First of all, the zone of direct influence of language on the emerging concepts and notions is distinguished. On the one hand, knowledge and information go through the verbal processing of speakers and become a linguistic form. On the other hand, the evolution of new concepts takes place using schemes that have existed until then, i.e., based on the direct influence of existing concepts in language. Therefore, both concepts and notions have a conventional linguistic form of expression. In this zone, the conceptual image of the world is completely connected with the conceptual-linguistic image of the world. There is another zone of linguistic influence, in which abstractions formed on the basis of generalizations of certain features of linguistic signs serve as a medium.

Meanwhile, the linguistic image of the world is formed due to the zones of direct and indirect influence of the two languages on the 
conceptual image of the world. Linguistic and conceptual images of the world are closely linked in the verbal phase.

In modern linguistics, along with the concepts of conceptual and linguistic description of the world, the concept of national world image is also widely used. It is known that all countries in the world differ from each other in terms of their socio-economic development, past history, cultural development and way of life, and have their own national worldview. The image of the national world is an informationemotional space, which is both virtual and real, which separates a person from where he lives and works and encounters a foreign culture. This includes all the vivid and potential perceptions of members of a particular cultural-national society of the cultural phenomenon (both national and individual). Language plays a major role in the verbalization of the national worldview. After all, language is the mediator of culture and its distributor. Language transmits the national cultural riches that it retains from generation to generation. In infants who begin to speak their source language, along with the native language, the general cultural experience inherited from their ancestors is also absorbed. Language is a practical, real consciousness, and the need to interact with other people, like language consciousness, arises because of the need to interact. Language is a means of communication between people and a direct expression of thought. The exchange of ideas can only be accomplished using language. Language is an existential form of thinking, and thinking is the content of language. The formation of consciousness in man and the emergence of language is the first step of culture. The formation and growth of language has a direct impact on the development of the spiritual image of people. Language directly contributes to the growth of cultural and spiritual ties among people. Language reflects the events that have taken place in society over the years and centuries. It collects and transmits information from ancestors to generations.

In studying the cultural image of the world, experts in linguocultural studies (N.M.Terebikhin, V.N.Toporova, G.D.Gachev) cite a number of cases:

1) language embraces the universal and their specific features, including the cultural image of the world;

2 ) in the cultural image of the world there will be meanings specific to the culture, cultural-valuable dominants, concepts that form certain types of culture, preserved and applied in the language;

3) the cultural image of the world does not represent a single image in the pattern of a single language culture, because representatives of different nationalities may have different values;

4) the cultural image of the world exists not only in the individual but also in the collective consciousness [7].

At this point, in linguocultural studies, the famous linguist A.A.Rltebnya introduced the hypothesis of the inner or outer form of the word is of great importance because the etymological analysis reveals the primary meaning of the word. This helps to identify important aspects of the ethnic worldview in language. The associations and semantic features that form the implicit form have a greater ethnocultural specificity than the denotative component of lexical essences; "The implicit form, when connected with the lexical essence, creates a peculiar twisting expression of the world through words" [8]. H.Khomskiy defines the internal form of the word as follows: "The implicit form of the 
word, the essence of the word or the image underlying its use can be determined only against the background of the material and spiritual culture, language system in which this word or combination of words came into being" [9]. The choice of the internal form of the word has social and cultural-historical aspects. In the analysis of the internal form of a word in linguistics, two trends are observed: the diachronic etymological interpretation of this concept and the state of synchronization of the internal form of language units with their content.

The internal form is aimed at establishing a certain connection in the language, which is important for the purposes of conveying a secondary nomination or system of relations (integral situation), which again helps to form a number of associative connections in the minds of language owners. Moreover, "the typified situation represented by the inner form will in this form include a certain value direction developed by social practice in the course of the historical development of that society, settled in the individual consciousness of previous ancestors"[10].

Thus, language is the most important means of communication between people, a tool for messaging ideas to others. Language is a mirror of national culture and a treasure that preserves it. The nature of the place where each nation lives, the economic system of the people, its folk works, literature, art, science, traditions, reflecting, collecting and transmitting from generation to generation is a national and cultural symbol of the language. Language is a mirror of culture. It reflects not only the world around which humanity exists, the living conditions, but also the self-awareness, mentality, national character, lifestyle, traditions, customs, spirituality, values and worldview.

\section{REFERENCES}

1. Sapir E. Selected works on linguistics and cultural studies. - M., 1993 --- p. 259-265)

2. Gasparov V.M. Introduction to sociogrammatics // Uchen. app. Pie. state un-that. Issue 425. Tr. in Russian and Slavic. philology. Linguistic row. V. 29 // Problems of the language system and its functionality. 1977.S. 24-45.

3. Wharf, Benjamin Lee, 1956, Language, Thought and Reality, Cambridge University Press: MIT Press. Edited by John B. Carroll.

4. Ter-Minasova S.G. Language and intercultural communication / S. G. TerMinasova. - M.: SLOVO / SLOVO, 2008 .-- S. 15.

5. Maslova V.A. "Conceptual Basics of Modern Linguistics" (Moscow: Flinta Publ., 2019.)

6. Kubryakova E.S. On cognitive linguistics and semantics of the term "cognitive" bulletin of VSU, a series of linguistics and intercultural communication, 2001, V. 1, - p. 4.

7. Karasik V.I. Language matrix of culture. Volgograd, 2012.

8. Mechkovskaya N.B. Social linguistics. I (2nd ed. - M., 2000. - 208 p.)

9. Chomsky N. Language and thinking. M., 1972 [a]. - 122 p.

10. Vezhbitska A. Language. Culture. Cognition. - M :: Languages of Russian culture, 1996. 